\title{
Optimising construction with self-compacting concrete
}

\section{David Rich MEng}

Research Engineer, Centre for Innovative and Collaborative Construction Engineering, School of Civil and Building Engineering, Loughborough University, UK

Jacqueline Glass BA, PhD, DipArch, CertHE, DipBRS, FHEA

Professor of Architecture and Sustainable Construction, School of Civil and Building Engineering, Loughborough University, UK

Alistair G. F. Gibb BSC, PhD, CEng, MICE, MCIOB

Professor of Construction Engineering Management, School of Civil and

Building Engineering, Loughborough University, UK

\author{
Christopher I. Goodier BEng, PhD, PGCert, MCIOB, MICT, FHEA \\ Lecturer in Structures and Materials, School of Civil and Building \\ Engineering, Loughborough University, UK \\ Graham Sander BSC, PhD \\ Professor of Hydrology, School of Civil and Building Engineering, \\ Loughborough University, UK
}

Self-compacting concrete or self-consolidating concrete (as it is known in North America) (SCC) is used on the basis of its unique properties of flowability, passability and resistance to segregation. It requires no external energy to achieve full compaction, so is advantageous on site, but there is evidence that its higher cost is a significant barrier to greater adoption. The research entailed work measurement of 14 UK single-family home residential projects (eliciting data on construction time and labour productivity) and cost modelling of three slab scenarios (exploring the relationship between material and labour costs). The study found SCC was placed up to $\mathbf{7 3 \%}$ faster than conventional concrete and, when labour and material costs are included, the supplier is able to price SCC to closely match conventional concrete, hence making SCC more viable for the contractor. This relationship between as-built costs for SCC and conventional concrete is clarified by developing $\boldsymbol{P}_{\text {max, }}$ providing a new mechanism for understanding project profitability and viability of SCC.

\section{Notation}

$a$

$\mathrm{C}$

$d$

$e$

L

M

$O_{\mathrm{V}}$

$O_{\mathrm{V}}^{\mathrm{C}}$

$O_{\mathrm{V}}^{\mathrm{S}}$

$P^{\mathrm{C}}$

$P_{\text {max }}$

$P^{\mathrm{S}}$

$p$

$r$

S

$T_{\text {PT2 }}$

$T_{\text {PL2 }}$

$t$ slab area

superscript indicating conventional

concrete construction

slab depth (m)

administrative costs to employ labour

labour cost $(£)$

material cost $(£)$

overhead cost $(£)$

overhead cost for conventional concrete construction (£)

overhead cost for self-compacting concrete construction $(£)$

conventional concrete price $\left(£ / \mathrm{m}^{3}\right)$ maximum permissible premium $\left(£ / \mathrm{m}^{3}\right)$ self-compacting concrete price $\left(£ / \mathrm{m}^{3}\right)$ concrete price $\left(£ / \mathrm{m}^{3}\right)$ rate of worker pay ( $£ / \mathrm{min})$ superscript indicating self-compacting concrete construction total pour time per $\mathrm{m}^{2}$ total labour time per $\mathrm{m}^{2}$ time to place $1 \mathrm{~m}^{2}$ of slab

\section{Introduction}

Self-consolidating concrete, also called self-compacting concrete (SCC), has been available in Japan, North America and Europe for over 20 years. It is used in many mainstream construction projects because of its flowing nature and early maturity; it is generally considered to be an innovative material that is more expensive than conventional concrete mixes. Higher initial material cost seems to be the most significant barrier to greater adoption (Concrete Society and BRE, 2005; Rich et al., 2010, 2012), but its placement is claimed to be faster and more reliable than conventional concrete (Khayat et al., 2001; Okamura and Ouchi, 2003). Therefore, directly comparing SCC with conventional mixes, simply on the basis of material cost, is inappropriate and inaccurate.

Most extant SCC research focuses primarily on understanding and optimising physical and structural properties; with little examination of its effect on commercial out-turn measures, such as the construction cost (including materials, labour and plant). This paper reports on research into SCC and conventional concreting methods in $14 \mathrm{UK}$ single-family home projects. Work measurement and cost modelling through scenario 
analysis captured data on material costs, placement rates, workers' activities and plant/truck movements, to identify any significant time and cost differences between SCC and conventional concrete.

\section{Commercial status of SCC in construction}

2.1 Physical properties and claimed benefits of SCC SCC requires no external energy to achieve full compaction and is characterised by four distinct properties: resistance to segregation, flowing ability, passing ability and early strength gain (Goodier, 2003; Skarendahl and Billberg, 2006). An extensive, global research base on SCC's structural and physical performance aspects has built on earlier Japanese research (e.g. De Schutter et al., 2008; Khayat, 1999; Okamura and Ouchi, 2003; Shobha et al., 2006) and accepted test methods and standards/codes of practice have emerged (e.g. ASTM and Rilem). This is essential to encourage use and ensure the consistency and durability of an emerging technology. SCC also facilitates more complex structures owing to its ability to flow, fill formwork and compact without external input (Goodier, 2003; Grimes, 2005). Reports suggest improved quality and homogeneity, resulting in improved durability, and resistance to degradation (Goodier, 2003; Henderson, 2000; Skarendahl and Billberg, 2006). Furthermore, virtual elimination of surface defects, such as blow-holes and honeycombing
(Gaimster and Foord, 2000; Goodier, 2003) is claimed through the removal of the compaction operation, which is dependent on operative ability (Concrete Society and BRE, 2005; Holton, 2003), and should reduce remedial work (Gaimster and Foord, 2000; Grimes, 2005). SCC enables the contractor to use less site equipment (Damtoft et al., 2008) such as vibrating tools that are synonymous with hand-arm vibration syndrome and the generation of noise, which can present a hazard to operatives and a disturbance to local communities (Bartos and Cechura, 2001; Skarendahl and Rilem, 2003; Walraven, 2003). Further to this, the simplification of the construction operation can enable operative numbers to be reduced (Damtoft et al., 2008; Goodier, 2003). Yet, despite these claims, there is relatively little evidence and few data on SCC's practical application within construction (e.g. Damtoft et al., 2008; Gaimster and Foord, 2000; Goodier, 2003; Henderson, 2000), as summarised in Table 1. Although significant work has been undertaken in Europe, notably the Brite EuRam project (Grauers, 2000), which explored many aspects of SCC application including productivity and economy, which quantify SCCs' effect in conventional construction processes, there remains a lack of UK research. However, extant publications are often subjective and imprecise, lacking detail about data derivation and often citing values from elsewhere without justification. Hence, it is inadvisable to make a case for SCC based on such incomplete data.

\begin{tabular}{|c|c|c|}
\hline Benefit & Level of improvement cited & Detail and reference source \\
\hline \multirow[t]{4}{*}{ Reduction of costs } & $15 \%$ reduction & $\begin{array}{l}\text { Early decision to use material in Swedish construction (Concrete } \\
\text { Society and BRE, 2005) }\end{array}$ \\
\hline & $21.4 \%$ reduction & $\begin{array}{l}\text { French comparison undertaken by Lafarge, SCC compared with } \\
\text { conventional concrete (Concrete Society and BRE, 2005) }\end{array}$ \\
\hline & $5-15 \%$ reduction & $\begin{array}{l}\text { SCCs at design stage derived from 'experience' within Europe } \\
\text { (Holton, 2003) }\end{array}$ \\
\hline & $5-15 \%$ reduction & $\begin{array}{l}\text { Comparison between SCC and conventional bridge construction } \\
\text { (Goodier, 2003) }\end{array}$ \\
\hline \multirow[t]{3}{*}{$\begin{array}{l}\text { Reduction in } \\
\text { construction time }\end{array}$} & 2.5 months & $\begin{array}{l}\text { French comparison undertaken by Lafarge, SCC compared with } \\
\text { conventional concrete (Concrete Society and BRE, 2005) }\end{array}$ \\
\hline & $\begin{array}{l}20 \% \text { reduction ( } 2 \cdot 5 \text { years build } \\
\text { reduced to } 2 \text { years) }\end{array}$ & $\begin{array}{l}\text { Live construction of Akashi-Kaikyo Bridge in Japan (Okamura and } \\
\text { Ouchi, 2003) }\end{array}$ \\
\hline & 22 months to 18 months & $\begin{array}{l}\text { SCC on construction of LNG tank for Osaka Gas Company } \\
\text { (Okamura and Ouchi, 2003) }\end{array}$ \\
\hline Labour reduction & 150 operatives reduced to 50 & $\begin{array}{l}\text { Live construction of Akashi-Kaikyo Bridge in Japan (Concrete Society } \\
\text { and BRE, 2005) }\end{array}$ \\
\hline Energy saving & $\begin{array}{l}20-30 \% \text { reduction. Greenhouse } \\
\text { gases also reduced }\end{array}$ & $\begin{array}{l}\text { SNRA report, result of reduced resources in construction (Goodier, } \\
\text { 2003) }\end{array}$ \\
\hline $\begin{array}{l}\text { Productivity } \\
\text { improvements }\end{array}$ & $\begin{array}{l}60 \% \text { improvement over } \\
\text { conventional concrete }\end{array}$ & $\begin{array}{l}\text { Observation of Swedish works on } 19 \text { bridges and house slabs } \\
\text { (Persson, 2001) }\end{array}$ \\
\hline
\end{tabular}

Table 1. Summary of the benefits of SCC, from the literature 


\subsection{Factors affecting the decision to use SCC}

SCC is considered a specialist material, only suitable for certain applications (Clear, 2006; Holton, 2003), but this view is slowly being dispelled through continued use in general construction (Williams, 2008) and high-profile projects, such as The Collection, Lincoln, UK (Grimes, 2005) and The Hepworth, Wakefield, UK. Here, SCC was selected in response to specific challenges, for instance to create very high-quality, complex and detailed facades. SCC is rarely selected as a 'first choice' construction option in its own right, yet the literature confirms that the material has a broader range of benefits than this 'single attribute' decision making might suggest (Williams, 2008). SCC should not be considered on first-cost alone (Concrete Society and BRE, 2005; Holton, 2003), however, misconceptions relate to poor knowledge and an apparent increase to project costs as a result of material price (Concrete Society and BRE, 2005; Rich et al., 2011, 2012), as SCC tends to be more expensive than conventional concrete in cost per sales by volume. Rich et al. (2012) developed this idea further through case studies and industry surveys by identifying three distinct circumstances for use

- strategic change from conventional methods as part of a balanced assessment of SCC and its effect on construction

- reactionary response to a specific issue or problem (problem solving)

- specification of SCC as a pre-conceived construction option.

Rich et al. (2012) conclude that strategic change is a direct result of considering SCC as a construction method rather than a material, invoking engagement with SCC earlier in the construction process during design and planning with greater potential to adapt construction to realise other benefits.

\subsection{Lack of practical evidence on construction process}

Concrete slab construction has six steps, whether using SCC or conventional concrete: material discharge, manipulation of material, compaction, levelling, finishing and curing. However, SCC 'performs' the compaction process itself and the manipulation, levelling and finishing are simplified. This simplification can remove several steps compared to conventional construction (Figure 1). SCC's free-flowing nature reduces the requirement for manual manipulation. SCC exhibits selflevelling traits, whereas conventional concrete requires extensive manipulation with rakes and shovels prior to compaction and striking off. Conventional concrete slab finishing requires two stages: initial finishing by manual floating; then, once adequate curing has occurred, power floating. SCC finishing uses a 'dappling' process; small surface waves are created to achieve a smooth and level finish, equivalent to power-floated flatness. Both methods then require curing.
A good research base exists on SCC's physical and structural properties, but there is still a need to explore the effects of SCC's different approach on the construction process systematically on live projects. No one has yet explored SCC's effect on project time and cost, including casting rates, labour efficiency and quality of construction. The next section explains the research approach through work measurement and cost modelling of UK residential projects.

\section{Research approach}

The aim of the research was to compare SCC with conventional concrete, identifying differences in time and cost, using a series of residential projects to provide real-life data. There were two phases: work measurement and cost modelling.

\subsection{Work measurement}

Work measurement establishes the time for a 'qualified' individual to complete a specified task at a defined level of performance (Currie, 1977; Drewin, 1982). The process comprises the following stages

(a) Selection of work to be measured (A.1): clarify exactly what is to be measured. Here, the intention is to compare SCC with conventional concrete in the construction of single family homes.

(b) Defining the method (A.2): select the optimised construction process. In this case, use is made of traditional slab construction with conventional concrete and SCC construction methods.

(c) Establish work elements (A.3): break down the methods into elements which are easily measured, identifiable and transferable between construction options. Final quantification can only be confirmed when observations are complete.

(d) Measurement of elements (A.4): direct timing of an element of work. Success depends on clearly defined work elements with distinct start and finish points, incorporating a defined and detailed method of data capture. Standard rate of working and rest time are factored in.

(e) Obtaining a standard time (A.6): determine an overall time for the construction processes combining all measured elements and adjustments. Rationalisation of time measurements was on a unit area and volume basis.

\subsection{Selection of project cases and method used}

The study element must be built regularly with very similar or standardised methods; ground floor residential slabs satisfied these criteria, providing directly comparable, robust results that could compare the claimed benefits of SCC with conventional concrete. There are two distinct slab construction methods for the ground floors of houses in the UK: ground bearing in situ 


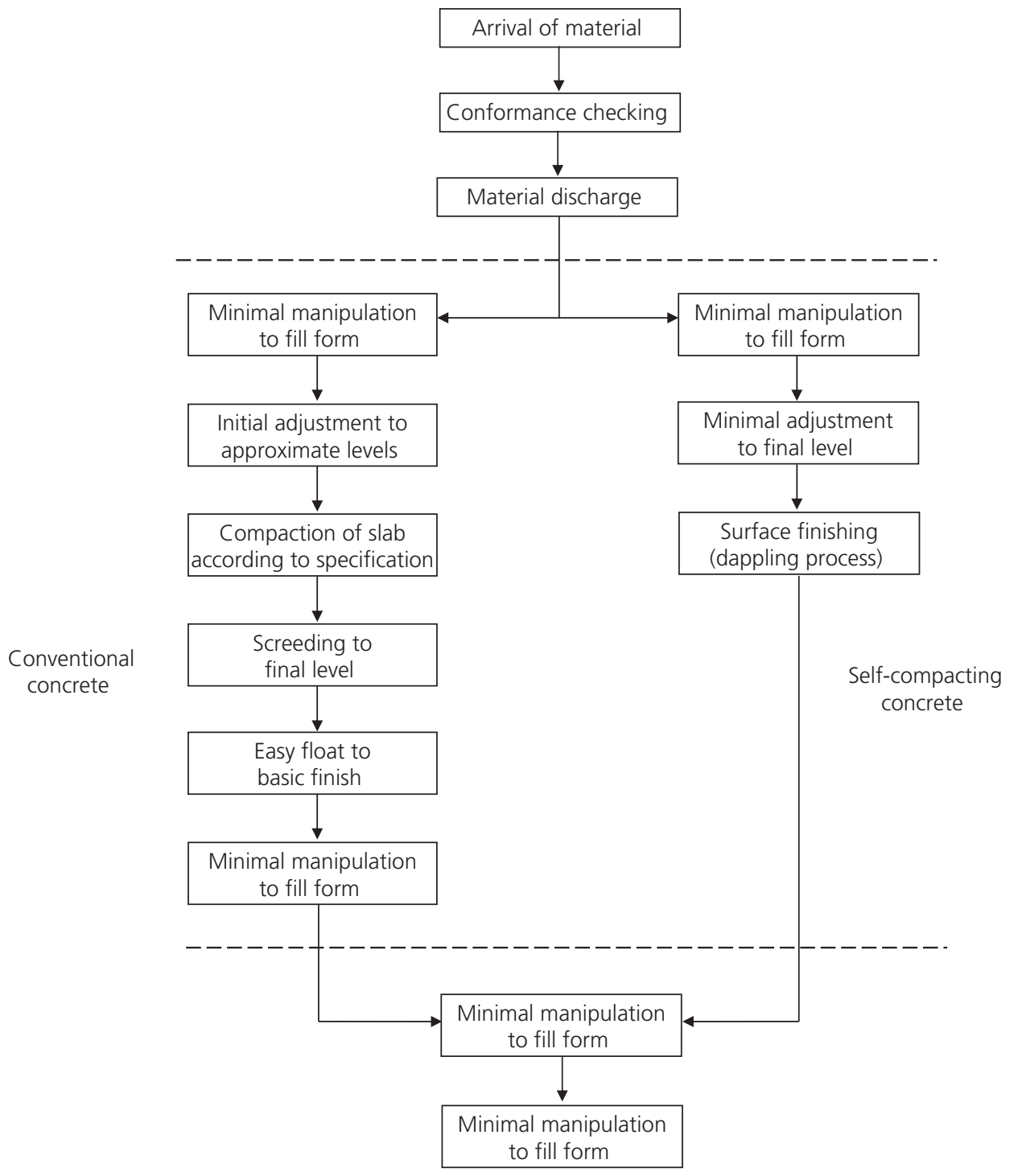

Figure 1. Breakdown of conventional concrete and SCC placing methods

(GB) or suspended (SS). The SS method typically uses precast beam and blocks with an in situ topping and SCC is used more often than GB slabs. The management structure for such projects is simpler than structural frame projects, leading to easier permissions for site observations. Although a number of parties are involved, it is only the contractor responsible for the placement of the concrete who experiences any changes to methods of working through using SCC. The contractor's primary concern is the strength and finish specifications (British and Eurocode standards along with National HouseBuilding Council (NHBC, 2011) standards), it is therefore only this contractor's work that needs to be observed and considered. In total, 14 separate slabs were investigated, six using conventional concrete mixes (ranging from C16/20 to C28/35) and eight using SCC over a 3-month summer period in 2010. The sites were within reasonable travelling distance from base, were comparable in size and design, and all involved experienced contractors. The processes were filmed to record the movement of materials, labour and plant. For each pour, records were made of total pour time, time from initial material discharge to curing, activity times, time for each individual construction activity to be completed, along with labour times, time on the pour and time actively working. To identify significant differences in construction protocols so that 
any anomalies through the analysis of times may be interrogated to determine the drivers, several additional observations were made, including slab dimensions and construction details, material design, labour, plant and ambient conditions.

\subsection{Developing cost model scenarios}

The cost differences between the two methods were determined using both the timings and labour/plant movement data captured on film along with additional cost data, facilitating a more holistic understanding. Cost modelling was an appropriate method, enabling rationalised comparisons based on realistic scenarios. Two conventional concrete scenarios illustrated variability in the power-floating operation, where completion is dependent on the rate of curing (dictated partly by ambient conditions). Only one scenario was needed for SCC as it does not require any break point once pouring has commenced. Each scenario was based on slabs of a similar type to those used in obtaining the time data. The slab design was an idealised suspended ground-floor residential slab, common to UK housebuilding, constructed using an insulated block and beam system with a concrete topping layer (to a size of $9 \mathrm{~m} \times 5 \mathrm{~m} \times 0.075 \mathrm{~m}=$ $45 \mathrm{~m}^{3}$ ), finished smooth to suit final finishes (Figure 2).

As-built cost data were developed from construction time data to describe the construction process. The study was extended by further and more detailed observations of the construction process, with an understanding of each step in the construction process and its requirements with respect to auxiliary items such as plant, labour, materials, and so on. This was where additional site observations provided deeper understanding of each construction activity. For each process, the cost to construct was developed considering material price (concrete and supplementary (curing agent, form release agents, and so on)), operative pay rates, volume of labour, plant and equipment costs (hire or purchase), site overheads, out-of-hours working and regional cost variations. Data were collected from material suppliers, contractors and pricing books, and were current at the first quarter of 2011. Currency of the data, the units of measurement and outlying factors that might influence the costs on a live project were verified. The eventual costs of each element were collated into a single cost to determine the difference between conventional and SCC methods.

\section{Results}

\subsection{Time study}

These results are based on direct observations of the construction of 14 residential slabs similar to that shown in Figure 3. In the majority of cases, the SS structures incorporated inverted $\mathrm{T}$ precast beams, with either concrete or insulated polystyrene infill blocks. Brick or block work was initially constructed from foundation level to two brick courses below the damp-proof course level. Precast beams were laid typically spanning between perimeter foundation walls to intermediate supporting columns or walls. Brickwork was laid to final

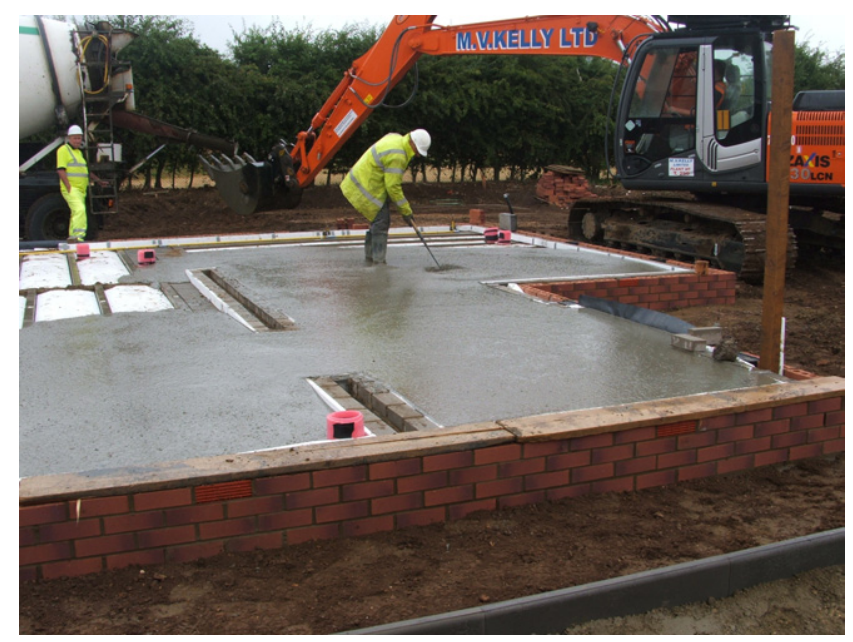

Figure 3. One of the residential sites used in the time study

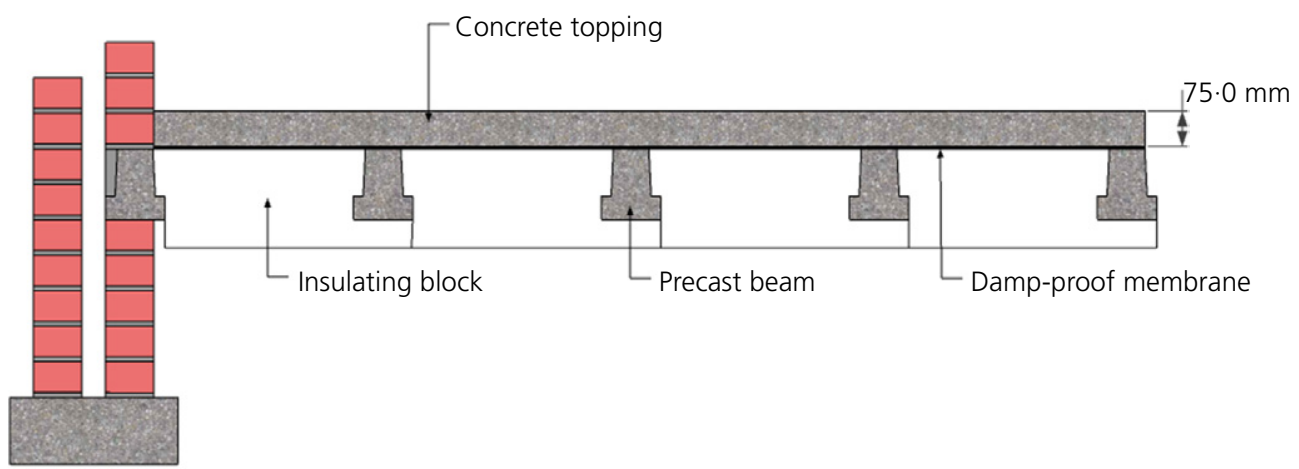

Figure 2. Representation of SS design 
finished slab level, and the infill blocks were installed. A damp-proof membrane was placed onto the block and beam structure overlapping onto the brickwork at damp-proof course level. In both approaches, concrete was discharged to the slab from the bucket of a $360^{\circ}$ excavator with no significant variation in discharge rate. Compaction of conventional concrete typically used mechanical poker vibrators or vibrating tamping rails.

The total construction time for each slab was determined from the film analysis from initial discharge to the final application of curing protocol, along with intermediate breakdowns of each distinct phase: placement, tamping, screeding, floating, power floating, dappling and curing. This provides a descriptive account, but does not enable direct comparisons to be made owing to the varying slab areas and depths, so the data have been rationalised. First, from a total time to an average time per unit area $\left(\mathrm{m}^{2}\right)$ and per unit volume $\left(\mathrm{m}^{3}\right)$ for each slab (the lower two rows in Tables 2 and 3) and second, the average construction time, taken across all instances of SCC slabs and conventional slabs, can be seen at the far righthand columns in Tables 2 and 3.
Direct comparison of the average construction times show that SCC produces a significant overall time saving over that of conventional concrete (36 s/unit area (SCC) compared to $2 \mathrm{~min}$ $26 \mathrm{~s}$ (conventional); and $7 \mathrm{~min} 35 \mathrm{~s} / \mathrm{unit}$ volume (SCC), compared to $30 \mathrm{~min} 16 \mathrm{~s}$ (conventional)). Figure 4 illustrates pour time $\left(T_{\mathrm{PT} 2}=\right.$ total pour time $\left./ \mathrm{m}^{2}\right)$ and labour time $\left(T_{\mathrm{PL} 2}=\right.$ total labour time $/ \mathrm{m}^{2}$ ) differences. SCC is $73 \%$ quicker and uses $70 \%$ less labour.

\subsection{Understanding the influence of material, plant and labour costs}

It was stated earlier that the high material cost of SCC is a barrier to adoption, so the time study data have been extended to include cost information. Three scenarios were developed from observations, as described in the research approach section (Figure 5, which includes both time and labour requirements)

- 'best case' conventional concrete slab

- 'worst case' conventional concrete slab

- SCC slab.

\begin{tabular}{|c|c|c|c|c|c|}
\hline $\begin{array}{l}\text { Slab code } \\
\text { number }\end{array}$ & $\begin{array}{l}\text { Pour time: } \\
\text { min:s }\end{array}$ & $\begin{array}{l}\text { Area: } \\
\mathrm{m}^{2}\end{array}$ & $\begin{array}{l}\text { Volume: } \\
\mathrm{m}^{3}\end{array}$ & $\begin{array}{c}\text { Rationalised construction } \\
\text { time: }(\min : s) / \mathrm{m}^{2}\end{array}$ & $\begin{array}{c}\text { Rationalised construction } \\
\text { time: }(\mathrm{min}: \mathrm{s}) / \mathrm{m}^{2}\end{array}$ \\
\hline CON1 & $82: 54$ & 41.83 & $3 \cdot 14$ & 01:59 & $26: 24$ \\
\hline CON2 & $86: 05$ & $37 \cdot 80$ & $2 \cdot 84$ & $02: 17$ & 30:19 \\
\hline CON3 & $80: 15$ & $37 \cdot 80$ & $2 \cdot 84$ & 02:07 & $28: 16$ \\
\hline CON4 & $47: 57$ & $16 \cdot 50$ & $1 \cdot 24$ & $02: 54$ & $38: 45$ \\
\hline CON5 & $47: 07$ & $16 \cdot 50$ & $1 \cdot 24$ & $02: 51$ & $38: 04$ \\
\hline CON6 & $84: 15$ & $56 \cdot 77$ & $4 \cdot 26$ & $01: 29$ & $19: 47$ \\
\hline \multicolumn{4}{|c|}{ Average construction time for all six slabs } & $02: 16$ & $30: 16$ \\
\hline
\end{tabular}

Table 2. Rationalised construction times for slabs using conventional concrete

\begin{tabular}{|c|c|c|c|c|c|}
\hline $\begin{array}{l}\text { Slab code } \\
\text { number }\end{array}$ & $\begin{array}{l}\text { Pour time: } \\
\text { min:s }\end{array}$ & $\begin{array}{l}\text { Area: } \\
\mathrm{m}^{2}\end{array}$ & $\begin{array}{l}\text { Volume: } \\
\mathrm{m}^{3}\end{array}$ & $\begin{array}{c}\text { Rationalised construction } \\
\text { time: }(\min : s) / \mathrm{m}^{2}\end{array}$ & $\begin{array}{c}\text { Rationalised construction } \\
\text { time: }(\min : \mathrm{s}) / \mathrm{m}^{3}\end{array}$ \\
\hline SCC1 & $28: 40$ & $36 \cdot 73$ & $3 \cdot 67$ & $00: 47$ & 07:49 \\
\hline SCC2 & $23: 15$ & $49 \cdot 49$ & 4.95 & $00: 28$ & $04: 42$ \\
\hline SCC3 & $45: 40$ & $69: 31$ & $5 \cdot 20$ & 00:40 & $08: 47$ \\
\hline SCC4 & 23:15 & $42 \cdot 80$ & $3 \cdot 21$ & 00:33 & $07: 15$ \\
\hline SCC5 & $30: 50$ & $42 \cdot 85$ & $3 \cdot 21$ & $00: 43$ & 09:36 \\
\hline SCC6 & $22: 15$ & $46 \cdot 33$ & $3 \cdot 47$ & $00: 29$ & $06: 25$ \\
\hline SCC7 & 23:30 & $41 \cdot 46$ & $3 \cdot 11$ & $00: 34$ & 07:33 \\
\hline \multicolumn{4}{|c|}{ Average construction time for all seven slabs } & $00: 36$ & $07: 26$ \\
\hline
\end{tabular}

Table 3. Rationalised construction times for slabs using SCC 


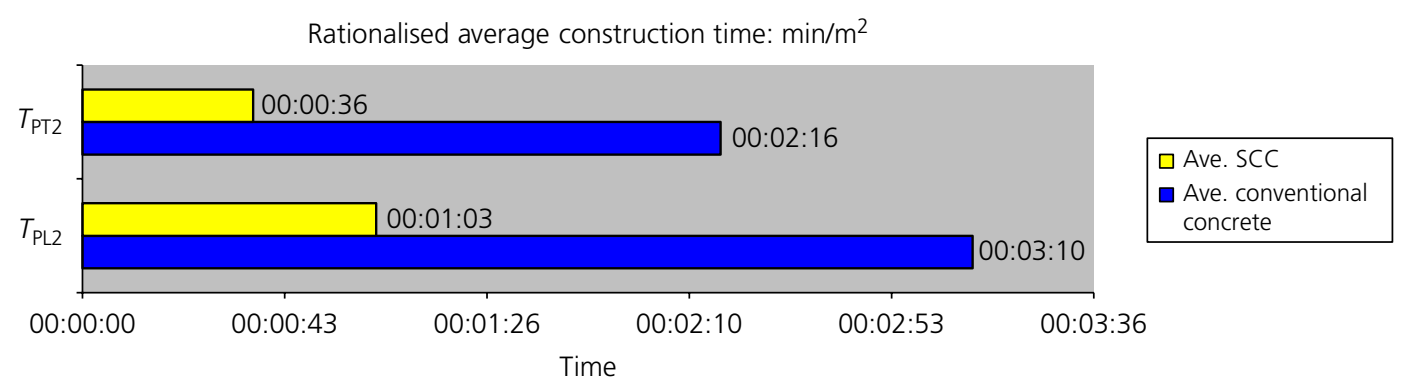

Figure 4. Comparison of average construction time for conventional and SCC methods, including power floating operation

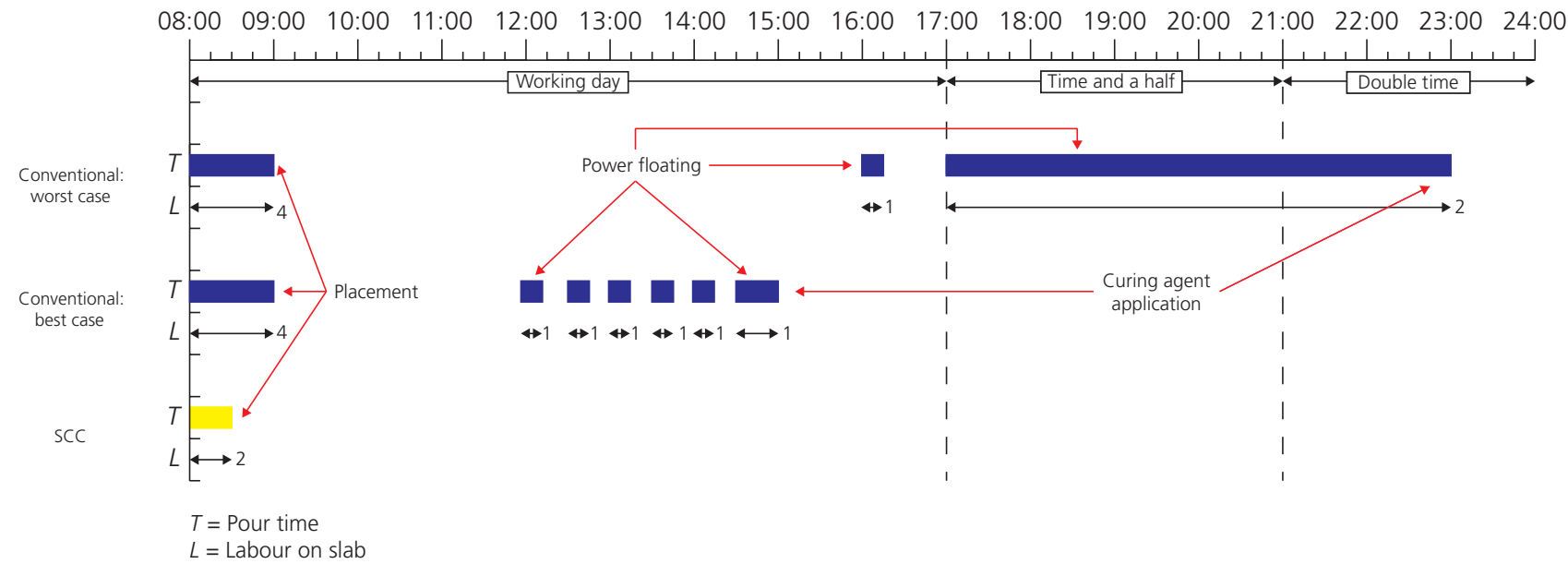

Figure 5. Gantt chart of idealised construction scenarios, with time and labour requirements

Construction with conventional concrete is susceptible to significant variation in the cost to construct, mainly due to the power-floating operation. In the worst-case scenario costs are raised by $72 \%$, which, if encountered on a number of slabs, would significantly increase total project costs. SCC provides a substantial saving, $£ 291.45$ for completed construction, over the worst-case scenario of conventional concrete. However, in the best-case scenario, SCC is more expensive by $£ 28.63$ (Table 4). All costs were current at first quarter of 2011.

This comparison enables prevalent factors in method choice to be determined. SCC reduces construction overheads and placement labour through the simplified construction process; however, they are not significant in the balance between options. Material price is the most significant factor for SCC; this reflects existing literature, which considers price as a major barrier to uptake (Concrete Society and BRE, 2005; Holton, 2003; Rich et al., 2012). The determining factor for conventional concrete is labour, where out-of-hours working is most influential. However, the relationship between out-ofhours working on conventional projects and the material price for SCC determines the tipping point between each method.

\subsection{The importance of $\boldsymbol{P}_{\max }$}

It has been possible to establish the maximum permissible premium $\left(P_{\max }\right)$ per unit volume $\left(\mathrm{m}^{3}\right)$ that can be applied to SCC by the supplier, such that the contractor can achieve parity between the as-built costs for both conventional and SCC methods (and therefore be at no overall disadvantage from using SCC). Here, $P_{\max }$ is determined with respect to slab size and labour rate, based on the construction of a $75 \mathrm{~mm}$ deep topping on block and beam construction (Figure 6).

In the 'best-case' scenario for conventional concrete, parity can be achieved by providing SCC at a $P_{\max }$ of $£ 29 \cdot 46 / \mathrm{m}^{3}$ above the price of conventional concrete. Figure 6 shows the 


\begin{tabular}{|c|c|c|c|c|}
\hline \multirow[b]{2}{*}{ Costs: $f$} & \multirow[b]{2}{*}{ SCC } & \multicolumn{3}{|c|}{ Conventional } \\
\hline & & Worst & Best & \\
\hline Overheads & $2 \cdot 00$ & $43 \cdot 33$ & $43 \cdot 33$ & \\
\hline Placement labour & $15 \cdot 22$ & $57 \cdot 02$ & $57 \cdot 02$ & \\
\hline Power float labour & 0.00 & $2 \cdot 37$ & $14 \cdot 20$ & \\
\hline Out of hours labour premium & 0.00 & $334 \cdot 00$ & & \\
\hline Material & 380.63 & $252 \cdot 59$ & 252.59 & \\
\hline Curing labour & $n / a$ & Included in $\mathrm{O} / \mathrm{H}$ & 2.09 & \\
\hline Curing agent & $6 \cdot 75$ & $6 \cdot 75$ & $6 \cdot 75$ & \\
\hline Total & $404 \cdot 60$ & $696 \cdot 05$ & $375 \cdot 97$ & \\
\hline Saving from using SCC compared with conventional concrete & n/a & +291.45 & -28.63 & $-7 \%$ \\
\hline
\end{tabular}

Table 4. Costs for the three slab scenarios

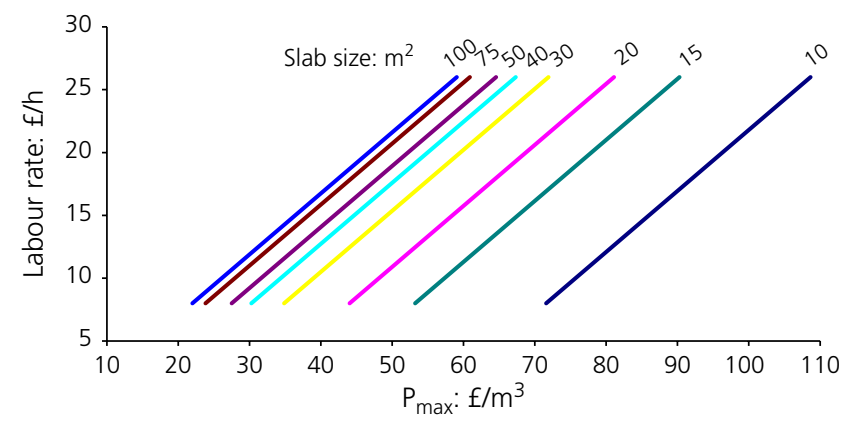

Figure 6. Graph of $P_{\max }$ for varying slab size and labour rate (slab depth $=0.075 \mathrm{~m}$ )

relationship between slab size and $P_{\max }$, as slab size increases $P_{\max }$ decreases, effectively reducing the cost benefit of the SCC method. However, at low labour rates $P_{\max }$ is small because of the relationship that exists between material and labour cost, material price is the significant variable with SCC and labour with conventional concrete. When labour rate is low the difference between material and labour is at its greatest, which reduces $P_{\max }$ as this is a function of the difference in as-built construction costs determined by material and labour costs. As labour costs increase for the same sized slab, material costs remain constant. This in turn reduces the as-built cost difference between methods and enables $P_{\max }$ to be maintained at a higher value.

As slab size increases, $P_{\max }$ decreases. However, for the same slab, there can be two different timings and costs from extended working hours due to varying ambient conditions. Therefore, the relationship between $P_{\max }$ and slab size in these circumstances may vary. If out-of-hours working is incurred when constructing with conventional concrete (Table 4) the relationship between material cost and labour rate varies, where initially the difference in constructed costs will reduce to a point where conventional construction costs will exceed SCC, the worst-case scenario. The amount of out-of-hours working is determined by two factors: ambient conditions and slab size. If ambient conditions remain constant for slabs of increasing size, the increase in out-of-hours working would be proportional to slab size. $P_{\max }$ is directly related to these factors and would see a change in the relationship to slab size, increasing rather than decreasing (Figure 7), improving the as-built cost benefit of SCC once out-of-hours working is required.

The maximum permissible premium, $P_{\max }$, can now be calculated for residential suspended slab construction to find the tipping point between extra material cost of SCC and the extra labour costs by using conventional concrete. $P_{\max }$ can determine when SCC would become a viable selection.

For single-family homes, where the slab areas do not exceed $65-75 \mathrm{~m}^{2}$ with a depth of approximately $300 \mathrm{~mm}$, the $P_{\max }$ relationship can be described mathematically based upon the total cost to place concrete into the slab, $T(£)$, shown in Equation 1.

1. $T=O_{\mathrm{V}}+L+M$

where $O_{\mathrm{V}}$ denotes the overhead costs $(\mathfrak{f}), L$ is the labour cost $(\mathfrak{f})$ and $M$ is the material cost (£).

Considering each term in detail, $O_{\mathrm{V}}$ is the construction overhead costs $(£)$ derived from on-site observations representing cost of plant and equipment. $L$ is the labour cost (£), a product of the size of the slab and the time taken to place $1 \mathrm{~m}^{2}$, labour operatives' rate of pay and the cost to employ, therefore

2. $L=t \times a \times e \times r$ 


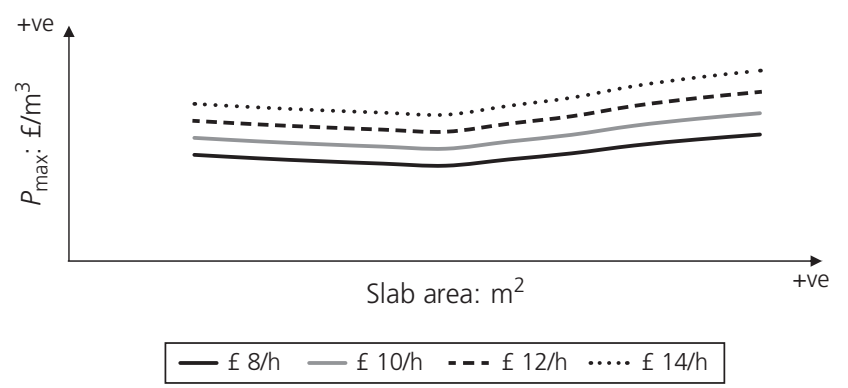

Figure 7. Variation of $P_{\max }$ resulting from out-of-hours working, with respect to increasing slab area, for a range of operative pay scales

where $t$ is the time to place $1 \mathrm{~m}^{2}$ of slab (rationalised to a $\mathrm{min} /$ $\mathrm{m}^{2}$ rate), $a$ is the slab area $\left(\mathrm{m}^{2}\right), r$ is the rate of worker pay $(£ / \mathrm{min})$ and $e$ is the administrative costs to employ labour.

Material cost $(M)$ is a factor of slab area, slab depth and the retail price of concrete, as follows

\section{3. $M=a \times d \times p$}

where $a$ is the slab area $\left(\mathrm{m}^{2}\right), d$ is the slab depth $(\mathrm{m})$ and $p$ is the concrete price $\left(£ / \mathrm{m}^{3}\right)$. The overarching formula for calculating total placement cost remains constant but the contributing times and costs between conventional and SCC methods vary, therefore, for conventional construction

4. $T=O_{\mathrm{V}}^{\mathrm{C}}+L^{\mathrm{C}}+M^{\mathrm{C}}$

and for SCC construction

5. $T=O_{\mathrm{V}}^{\mathrm{S}}+L^{\mathrm{S}}+M^{\mathrm{S}}$

Parity between construction methods, when it is possible to derive $P_{\max }$, is achieved when the total placement costs for both conventional and SCC are equal, therefore when Equation 4 is equal to Equation 5, as shown in Equation 6

6. $T^{\mathrm{C}}=T^{\mathrm{S}}$

Rearranging Equation 6 produces Equation 7, which is used to attain the value of $P_{\max }$

7. $p^{\mathrm{S}}-p^{\mathrm{C}}=\frac{O_{\mathrm{V}}^{\mathrm{C}}-O_{\mathrm{V}}^{\mathrm{S}}}{a d}+\frac{\operatorname{er}\left(t^{\mathrm{C}}-t^{\mathrm{S}}\right)}{d}$

where $p^{\mathrm{S}}-p^{\mathrm{C}}=P_{\max }$, the maximum permissible premium to maintain parity between both construction methods.
Respectively $t^{\mathrm{C}}$ and $t^{\mathrm{S}}$ can be replaced by the values of $340 / 60$ and 72/60, respectively, which have been determined through detailed analysis of observations of suspended block and beam slabs construction.

By not exceeding $P_{\max }$, the supplier helps the contractor exploit the benefits of SCC to deliver a faster, higher quality slab at the same overall cost as conventional concrete. The existence and importance of this calculation has not been acknowledged in previous SCC research.

\section{Discussion}

Using time study of 14 residential slabs and cost modelling of three scenarios, SCC has been shown to improve construction times significantly as first proposed by Henderson (2000), Goodier (2003) and Holton (2003). In this research, SCC reduces construction by up to $70 \%$ compared to conventional concrete owing to its ease of placement and simplified construction process. Conventional methods combine compaction and levelling processes through tamping and screeding, a highly intensive and physically demanding activity; this intensity was apparent in the manipulation of the concrete - it requires more physical effort to manually level and power float the slab, whereas SCC's fluid nature requires minimum work (dappling) to achieve a similar result. The literature also claims that material cost was a prohibitive factor in SCC's further adoption (Concrete Society and BRE, 2005; Rich et al., 2012). The three cost modelling scenarios have demonstrated that financial savings can be realised through SCC, subject to several conditions. The 'best-case' scenario for conventional construction was marginally cheaper than SCC considering all factors (i.e. material, plant and labour costs), but when out-ofhours working was required to complete the conventional concrete placement, SCC would result in significant savings. This offers new and insightful findings to a research field previously dominated by physical and structural testing. This research has also identified an important new variable, $P_{\max }$, describing the relationship between labour and material costs, such that the potential cost saving per $\mathrm{m}^{3}$ from using SCC can now be identified and understood.

There is also a wider implication: the combination of SCC's time and potential cost savings alongside its reliability and predictability mean that construction variations and associated risks can also be reduced. The inherent variability of conventional, in situ concrete construction justifies the use of the more predictable and reliable SCC method. SCC could increase the confidence of the project team in pre-project planning and cost estimation, thereby avoiding expensive outof-hours working. Considering the wider consequences of delays, there is potential for delays to follow-on trades, which may have an impact on the project's critical path. Such delays 
potentially incur costs which would far outweigh the additional material cost of SCC (e.g. total site running costs and potential penalties for late completion). SCC can shorten the critical path: it is faster with fewer operatives.

\section{Limitations of the study}

The main limitation is that the cases were all based in the UK, so caution should be exercised before extrapolating the results to other countries. Furthermore, work measurement typically has limitations relating to process, subject of the study and generalisation as explained further below.

- The study observed operatives with the potential for work rates to increase from constant observation. In mitigation, instances of obvious enhanced speed were noted and negated during analysis.

- Site observations, data capture and analysis and interpretation of results were all by the same person to provide continuity. Although checking procedures were in place, additional observers could have been used to verify the data.

- Activity timings were based on observations of when each activity started and finished, with times being recorded to the nearest $5 \mathrm{~s}$, relying on the observer to identify the end points.

- A sample size of 14 slabs, although modest, has provided sufficient data to address concerns of unrepresentative sampling. The selection of a generic building type responded to gaps in the literature. This has produced robust findings, but any further generalisation of results would require additional analysis.

- The time study required the breakdown of the operation into individual elements or activities; these were individually timed and combined to establish total construction time. However, there was always more than one operative and often a number of concurrent activities, so construction was filmed and timings were noted when reviewing the films.

- Construction is inherently complex, involving numerous elements and the input of many parties, even for simple projects. While the optimum situation would have been the evaluation of a whole project from inception to completion, this was not practicable.

\section{Conclusion}

This research aimed to identify whether or not SCC had a quantifiable effect on construction, ostensibly because there was a lack of robust evidence in the literature to establish if this was the case. Using data from 14 residential concrete slabs, SCC has been shown to present significant time savings and, even if these may not always result in actual cost savings, then SCC can be priced to closely match conventional concrete project costs overall. The relationship between costs for SCC and conventional concrete for slabs has been clarified and a new mechanism for understanding profitability and viability of $\operatorname{SCC}\left(P_{\max }\right)$ has been presented.

The results also reinforce the case for considering SCC as a method rather than a material (Rich et al., 2012). Where operations are adapted to make the most of SCC's benefits, it can have a positive effect on construction time and cost. This was evident from the residential projects selected; the market for SCC for such slabs in the UK has been growing steadily, albeit the reasons for this were previously not well understood. Further research to examine the effects of SCC on flat slab construction is underway, where risk reduction may have a more significant effect and the larger slab sizes may prove more competitive for SCC. While extending the work to different slab types and other construction elements such as walls and footings would also be worthwhile, the development of an ideal or best practice model for design and planning of SCC and how to adapt construction practices would also be a useful contribution to knowledge and practice.

\section{Acknowledgements}

The authors would like to acknowledge the contribution from Lafarge Aggregates Ltd (now Lafarge-Tarmac) and all the project staff. This work is part of an engineering doctorate funded by the UK Research Council (EPSRC) by way of Loughborough University's Centre for Innovative and Collaborative Construction Engineering.

\section{REFERENCES}

Bartos PJM and Cechura J (2001) Improvement of working environment in concrete construction by the use of selfcompacting concrete. Structural Concrete 2(3): 127-132. Clear CA (2006) Fact Sheet 5: Self-Compacting Concrete (SCC). British Cement Association, Camberley, UK. Concrete Society and Building Research Establishment (BRE) (2005) Self-compacting Concrete: A Review. The Concrete Society and BRE, Camberley, Surrey, UK, Report of a joint working group, Technical Report No. 62.

Currie RM (1977) Work Study. Pitman, London, UK.

Damtoft JS, Lukasik J, Herfort D, Sorrentino D and Gartner EM (2008) Sustainable development and climate change initiatives. Cement and Concrete Research 38(2): 115-127.

De Schutter G, Bartos P, Domone P and Gibbs J (2008) Selfcompacting Concrete. Whittles Publishing, Dunbeath, UK.

Drewin FJ (1982) Construction Productivity: Measurement and Improvement Through Work Study. Elsevier, Oxford, UK.

Gaimster R and Foord C (2000) Self-compacting concrete. Concrete 34(4): 23-25.

Goodier Cl (2003) Development of self-compacting concrete. Proceedings of the Institution of Civil Engineers Structures and Buildings 156(4): 405-414. 
Grauers M (2000) Rational Production and Improved Working Environment Through Using Self Compacting Concrete. Brite EuRam, Brussels, Belgium, Brite EuRam Proposal No. BE9603801.

Grimes P (2005) A vision for Lincoln. Concrete 39(1): 10-12. Henderson N (2000) Self-compacting concrete at Millennium Point. Concrete 34(4): 26-27.

Holton I (2003) Interim Report Detailing the Effects of SCC on the Construction Process. Department of Trade and Industry and BRE, Watford, UK.

Khayat KH (1999) Workability, testing and performance of self-consolidating concrete. ACI Materials Journal 96(3): 346-353.

Khayat KH, Paultre P and Tremblay S (2001) Structural performance and in-place properties of self-consolidating concrete used for casting highly reinforced columns. $A C I$ Materials Journal 98(5): 371-378.

NHBC (National House-Building Council) (2011) NHBC Standards 2011. NHBC, Milton Keynes, UK. See http:// www.nhbc.co.uk/ (accessed 26/03/2012).

Okamura H and Ouchi M (2003) Self-compacting concrete. Journal of Advanced Concrete Technology 1(1): 5-15.

Persson B (2001) A comparison between mechanical properties of self-compacting concrete and the corresponding properties of normal concrete. Cement and Concrete Research 31(2): 193-198.

Rich D, Williams D, Glass J, Gibb AGF and Goodier Cl (2010) To SCC or not to SCC? UK contractors' views. In Proceedings of SCC2010: 6th International Rilem
Symposium on Self-Compacting Concrete and 4th North American Conference on the Design and Use of SCC (Khyat K and Feys D (eds)). Springer, New York, USA, pp. 647-654.

Rich D, Glass J, Gibb AF and Goodier Cl (2011) The self-compacting method: concrete that can save you time and effort. Concrete 45(12): 24-27.

Rich D, Glass J, Gibb AF and Goodier Cl (2012) UK contractors' views on self-compacting concrete in construction. Proceedings of the Institution of Civil Engineers Construction Materials 165(4): 201-210, http://dx.doi.org/ 10.1680/coma.10.00036.

Shobha M, Harish Mohan D and Raju PSN (2006) Aggregate size and behaviours of self-compacting concrete. Proceedings of the Institution of Civil Engineers - Construction Materials 159(4): 147-152, http://dx.doi.org/10.1680/coma.2006.159. 4.147 .

Skarendahl A and Billberg P (2006) Casting of Self Compacting Concrete: Final Report of Rilem Technical Committee 188-CSC. Rilem Publications, Bagneux, France, Rilem Report 35.

Skarendahl A and Rilem (2003) The present - the future. Rilem Proceeding Pro 33. Rilem Publications, Bagneux, France, pp. 6-14.

Walraven J (2003) Structural aspects of self-compacting concrete. In Proceedings of the 3rd International Rilem Symposium on Self-Compacting Concrete. Rilem Publications, Bagneux, France, pp. 15-22.

Williams D (2008) Self-compacting concrete benefits: leeds Echo 2 project. Concrete 42(2): 14-15.

\section{HOW CAN YOU CONTRIBUTE?}

To discuss this paper, please email up to 500 words to the editor at journals@ice.org.uk. Your contribution will be forwarded to the author(s) for a reply and, if considered appropriate by the editorial board, it will be published as discussion in a future issue of the journal.

Proceedings journals rely entirely on contributions from the civil engineering profession (and allied disciplines). Information about how to submit your paper online is available at www.icevirtuallibrary.com/page/authors, where you will also find detailed author guidelines. 